Document downloaded from:

http://hdl.handle.net/10251/159149

This paper must be cited as:

Sala-Mira, I.; Diez, J.; Ricarte Benedito, B.; Bondía Company, J. (2019). Sliding-mode disturbance observers for an artificial pancreas without meal announcement. Journal of Process Control. 78:68-77. https://doi.org/10.1016/j.jprocont.2019.03.008

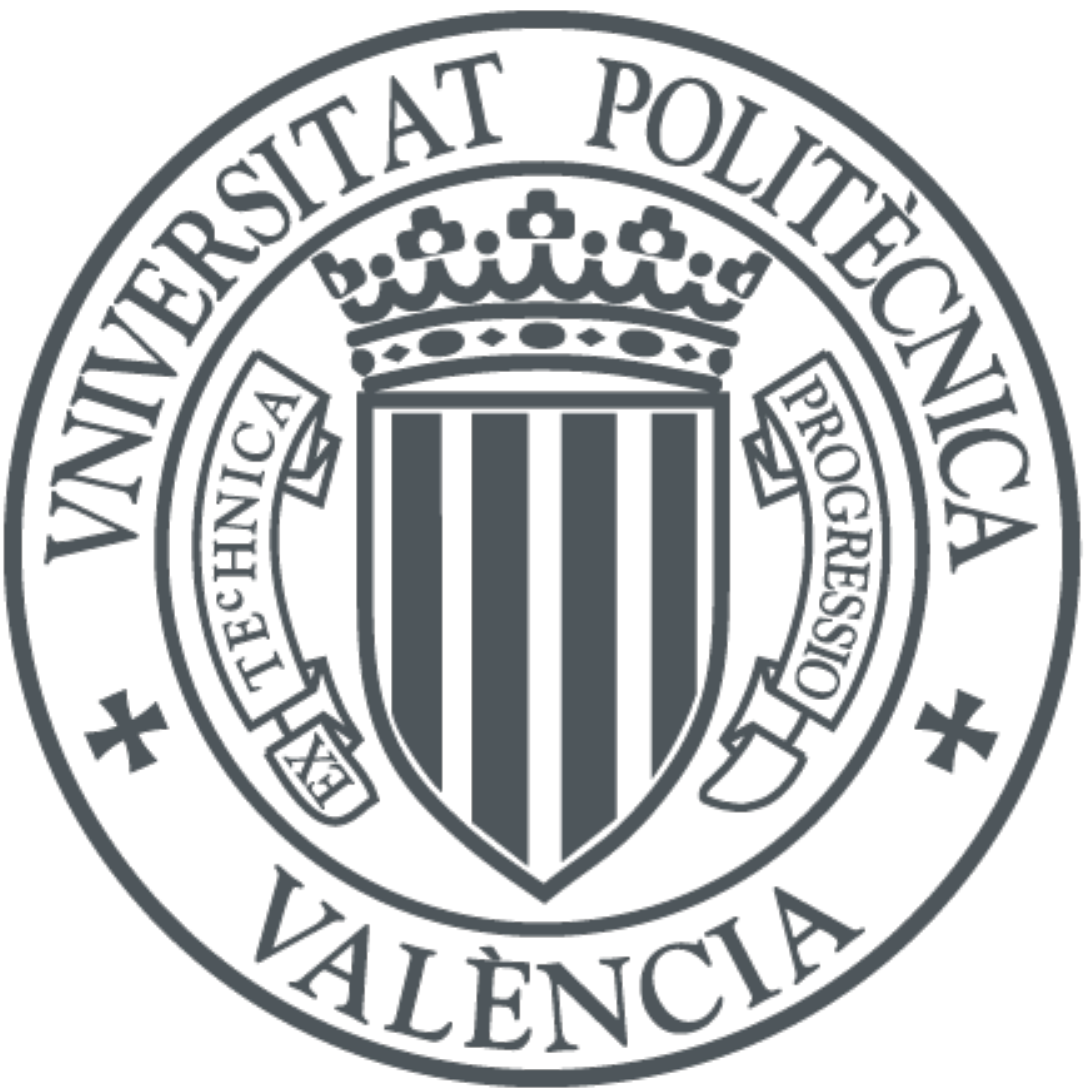

The final publication is available at

https://doi.org/10.1016/j.jprocont.2019.03.008

Copyright Elsevier

Additional Information 


\title{
Sliding-mode disturbance observers for an artificial pancreas without
} meal announcement

\author{
Iván Sala-Mira a , José-Luis Díez ${ }^{\mathrm{a}, \mathrm{c}}$, Beatriz Ricarte ${ }^{\mathrm{b}, \mathrm{c}}$, Jorge Bondia ${ }^{\mathrm{a}, \mathrm{c}, *}$ \\ a Instituto Universitario de Automática e Informática Industrial, Universitat Politècnica de València, Camino de Vera, s/n, 46022, Valencia, Spain \\ ${ }^{\mathrm{b}}$ Instituto Universitario de Matemática Multidisciplinar, Universitat Politècnica de València, Camino de Vera, s/n, 46022, Valencia, Spain \\ c Centro de Investigación Biomédica en Red de Diabetes y Enfermedades Metabólicas Asociadas (CIBERDEM), Instituto de Salud Carlos III, 28028, Madrid, \\ Spain
}

92 A R T I C L E I N F O

\section{Introduction}

\section{Article history:}

Received 22 July 2018

Received in revised form 1 March 2019

Accepted 12 March 2019

Available online $\mathrm{xxx}$

\section{Keywords:}

unannounced artificial pancreas

sliding mode observer

meal detection

postprandial control

\begin{abstract}
A B S T R A C T
Carbohydrate counting is not only a burden for patients with type 1 diabetes, but estimation errors in meal announcement could also degrade the outcomes of the current hybrid closed-loop systems. Therefore, removing meal announcement is desirable. A novel control system is addressed here to face postprandial control without meal announcement. The proposed system grounds on two applications of the sliding mode observers in dealing with disturbances: first, the equivalent output technique is used to reconstruct the meal rate of glucose appearance via a first order sliding mode observer; second, a supertwisting-based residual generator is used to detect the meals. Subsequently, a bolusing algorithm uses

Q1 the information of the two observers to trigger a series of boluses based on a proportional-derivativelike strategy. An in silico validation with 30 patients in a 30-day scenario reveals that the meal detector algorithm achieves a low rate of false positives per day (0.1 (0.1), mean (SD)) and a detection time of 28.5(6.2) min. Additionally, the bolusing algorithm fulfills a non-statistically different mean glucose than the hybrid counterpart with bolus misestimation (146.69 (12.20) mg/dL vs. 144.28 (11.01) $\mathrm{mg} / \mathrm{dL}, p>0.05)$, without increasing hypoglycemia $(0.029(0.077)$ vs. $0.004(0.014) \%, p>0,05)$, although at the expense of a slightly higher time in hyperglycemia $(22.51(8.72) \%$ vs. $18.65(7.89) \%, p<0.05)$ due to the conservative tuning of the bolusing algorithm for the sake of safety.
\end{abstract}

(c) 2019 Published by Elsevier Ltd.
In artificial pancreas systems, insulin action on lowering glucose is delayed because of the subcutaneous absorption lag and the glucose diffusion lag in continuous glucose monitoring sensor readings [1]. This delayed action is critical after meal consumption since it leads to a rapid rise of glucose, increasing the risk of suffering the hyperglycemia-related long-term complications such as retinopathy, nephropathy, neuropathy or heart disease [2]. Additionally,

Abbreviations: AUC, Area Under the Curve; CF, correction factor; FA, mealannouncement-free automatic system; FOSMO, first order sliding mode observer; FP, false positive; FN, false negative; GESO, Generalized Extended State Observer; ICR, insulin-to-carbohydrate ratio; IFB, Insulin Feedback; IB, main controller with Ideal Bolus; IOB, Insulin on board; IVP, Identifiable virtual patient; MB, main controller with Misestimated Bolus; NB, main controller with No Bolus; $\mathrm{R}_{\mathrm{A}}$, meal rate of glucose appearance; RMSE, root mean squared error; ST, super-twisting; SMRC, Sliding Mode Reference Conditioning; TDI, Total Daily Insulin; TP, true positive.

* Corresponding author.

E-mail addresses: ivsami@upv.es (I. Sala-Mira), jldiez@isa.upv.es (J.-L. Díez), bearibe@mat.upv.es (B. Ricarte), jbondia@isa.upv.es (J. Bondia). stacked insulin in the subcutaneous depot, i.e., the insulin-on-board (IOB), acts beyond meal absorption, leading to late postprandial hypoglycemia events [3] which could cause, in the severe cases, comma or even death.

Hybrid closed-loop systems cope with that delay by delivering an insulin bolus at meal time. Those systems rely on an accurate carbohydrate meal content estimation by the patient. However, carbohydrate counting is a burden for subjects and they are prone to either underestimate high-carbohydrate meals or, especially for adolescents, skipping meal announcement, leading to hyperglycemia events [4]. Therefore, removing meal announcement is desirable.

Several approaches in literature only utilize glucose measurement to detect meals and/or delivering boluses: Dassau et al. [5] suggest a voting system between four meal detection methods based on backward glucose differentiation and glucose estimation by Kalman Filter; Lee et al. [6] utilize the first and second glucose derivatives and some thresholding criterion to deliver meal boluses; and a Lagrangian interpolation polynomial is used in Harvey et al. [7] to compute glucose derivatives. Other techniques 


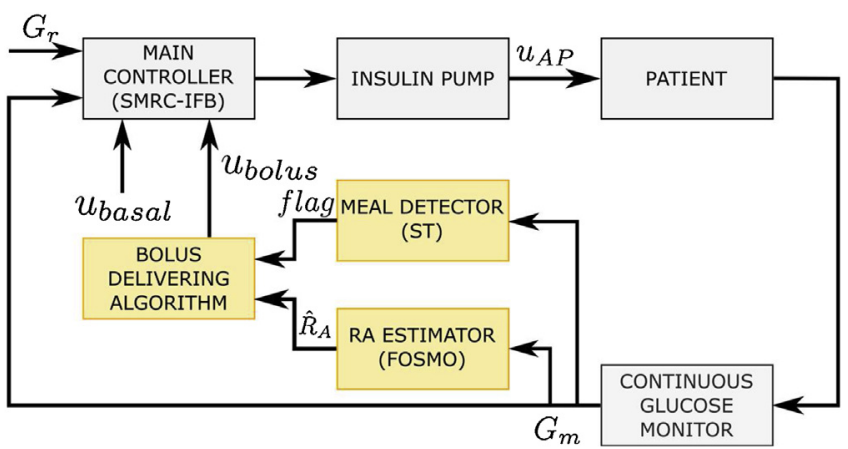

Fig. 1. Overview of the proposed meal-announcement-free artificial pancreas system. Diagram where the main parts of the system are depicted: main controller, super-twisting (ST)-based meal detector module and first order sliding mode observer (FOSMO)-based rate of glucose appearance $\left(R_{A}\right)$ estimator. The contributions of this paper are highlighted in orange

employ the estimated rate of meal glucose appearance $\left(R_{A}\right)$ since it provides information about meal absorption dynamics. For instance, the variable state dimension Kalman filter in [8] or the unscented Kalman filter in $[9,10]$.

In a previous work [11], the authors assessed the viability of a linear disturbance observer, named generalized extended state observer (GESO), to estimate the $R_{A}$. Although performance metrics were near off-line estimation techniques reported in [12], the estimation was affected by uncertainty and linearization errors. Therefore, a nonlinear observer approach is studied in this paper.

Sliding mode observers (SMO) exhibit inherent robustness properties to certain disturbances [13]. SMO can reconstruct disturbances by means of the equivalent output injection term [14] and they are suitable for robust residual generator [15]. This work exploits those applications to build to remove the meal announcement. On the one hand, an estimation of the $R_{A}$ is obtained via a first order sliding mode observer (FOSMO). On the other hand, a meal detector algorithm is proposed based on a super-twisting observer (ST) to detect the faults (meals). Finally, the meal detector algorithm and the $R_{A}$ estimation are fed to a bolusing algorithm aimed at reducing time in hyperglycemia without increasing hypoglycemia events regarding the hybrid counterpart. In all cases the Sliding Mode Reference Conditioning-augmented Insulin Feedback (SMRC-IFB) controller, assessed in [16], is used.

The paper is organized as follows. In Section 2, each module conforming the meal-announcement-free artificial pancreas and the conditions for the validation tests are detailed. In Section 3, the results of each comparative analysis are drawn. Finally, Section 4 closes the paper and considers some future research.

\section{Materials and methods}

\subsection{System structure}

The proposed system consists of four modules (see Fig. 1): 1) the main controller based on the SMRC-IFB assessed in [16], 2) a $R_{A}$ estimator based on a FOSMO; 3) a ST-based residual generator meal detector and 4) the bolusing algorithm. In the following sections, a description of each module as well as, the design model, are presented.

\subsection{Design model}

The Identifiable Virtual Patient (IVP) model [17] is selected to design the main controller and the $R_{A}$ estimator since it is a tradeoff
Table 1

Parameters of the IVP model resulted from the two-step optimization.

\begin{tabular}{lll}
\hline Parameter & Value & Units \\
\hline$\tau_{1}$ & 82.82 & $\min$ \\
$\tau_{2}$ & 21.43 & $\min$ \\
$p_{2}$ & $1.549 \cdot 10^{-2}$ & $\mathrm{~min}^{-1}$ \\
$S_{I}$ & $6.923 \cdot 10^{-4}\left(2.414 \cdot 10^{-4}\right)$ & $\mathrm{mL} / \mu \mathrm{U} / \mathrm{min}$ \\
$G E Z I$ & $3.0300 \cdot 10^{-8}$ & $\mathrm{~min}^{-1}$ \\
$E G P$ & 1.4880 & $\mathrm{mg} / \mathrm{dL} / \mathrm{min}$ \\
$C_{I}$ & 1116.1250 & $\mathrm{~mL} / \mathrm{min}$ \\
\hline
\end{tabular}

Identified parameters for the IVP model in (1). The insulin sensitivity $\left(S_{I}\right)$ is expressed as mean (SD).

option between Bergman's model [18] and Hovorka's model [19] in terms of accuracy and complexity. Its equations are

$$
\left\{\begin{array}{l}
\dot{I}_{S C}(t)=-1 / \tau_{1} I_{S C}(t)+1 / \tau_{1} u_{A P} / C_{I} \\
\dot{I}_{P}(t)=-1 / \tau_{2} I_{P}(t)+1 / \tau_{2} I_{S C}(t) \\
\dot{I}_{E F F}(t)=-p_{2} I_{E F F}(t)+p_{2} S_{I} I_{P}(t) \\
\dot{G}(t)=-\left(G E Z I+I_{E F F}(t)\right) G(t)+E G P+R_{A}(t)
\end{array},\right.
$$

where $I_{S C}(t)$ and $I_{P}(t)$ are subcutaneous and plasma insulin concentration $(\mu \mathrm{U} / \mathrm{mL})$, respectively; $I_{E F F}(t)$ is insulin effect in lowering glucose $\left(\mathrm{min}^{-1}\right)$ and $G(t)$ is plasma glucose concentration $(\mathrm{mg} / \mathrm{dL})$. $u_{A P}(t)$ is the exogenous subcutaneous insulin infusion $(\mu \mathrm{U} / \mathrm{min})$ and $R_{A}(t)$ is the rate of glucose appearance $(\mathrm{mg} / \mathrm{dL} / \mathrm{min})$. Finally, $\tau_{1}$ and $\tau_{2}$ are pharmacokinetic time constants ( $\left.\mathrm{min}\right), p_{2}$ is the kinetic rate for insulin action $\left(\mathrm{min}^{-1}\right), S_{I}$ is the insulin sensitivity $(\mathrm{mL} / \mu \mathrm{U} / \mathrm{min})$, GEZI is glucose effectiveness at zero insulin $\left(\mathrm{min}^{-1}\right)$, EGP is the hepatic glucose production $(\mathrm{mg} / \mathrm{dL} / \mathrm{min})$ and $C_{I}$ is the insulin clearance $(\mathrm{mL} / \mathrm{min})$.

Model (1) was identified for the average adult in the University of Virginia and Padova (UVa-Padova) simulator [20], under a 2-day scenario with 3 daily meals which considers hyperglycemia, hypoglycemia and normoglycemia conditions. Resulting parameters $\tau_{1}$, $\tau_{2}, p_{2}, C_{I}$, GEZI and EGP were used as population values for the design of the proposed system, whereas insulin sensitivity, $S_{I}$, was individualized for each subject in the study cohort. Remark that, the approach of individualizing only the insulin sensitivity (i.e. the model gain) is commonly addressed in the literature to personalize control-oriented models, see for example [21]. The identification procedure is based on the two-step approach in [17] to reduce the estimation error in the insulin pharmacokinetic parameters $\left(\tau_{1}, \tau_{2}\right.$ $\mathrm{y} C_{I}$ ) for the average patient: first, insulin subsystem parameters were estimated by minimizing the root mean squared error (RMSE) between the estimated plasma insulin and the real value computed by the simulator. The second step minimizes the RMSE between the estimated glucose measurement and the real glucose computed by the simulator to estimate $p_{2}, G E Z I, E G P$ and $S_{I}$ while insulin pharmacokinetic parameters were kept fixed according to the first step. Note that $R_{A}(t)$ was generated by UVA-Padova simulator in this step. Remark that the above procedure, although improving identification for the average patient, is not a guarantee of a better estimation for other patients when the average model is used as population model for algorithms design.

The identified parameters (see Table 1), are in the range of other results in the literature [17]. Further, the goodness of fit is $84.99 \%$ for $G(t)$ and $98.63 \%$ for $I_{p}(t)$.

\subsection{Main controller}

The SMRC-IFB control consists of a PD controller and two insulin limitation layers (see Fig. 2), Sliding Mode Reference Conditioning (SMRC) and Insulin Feedback (IFB), which constrain PD insulin infusion depending on insulin-on-board estimation (IOB) and plasma 


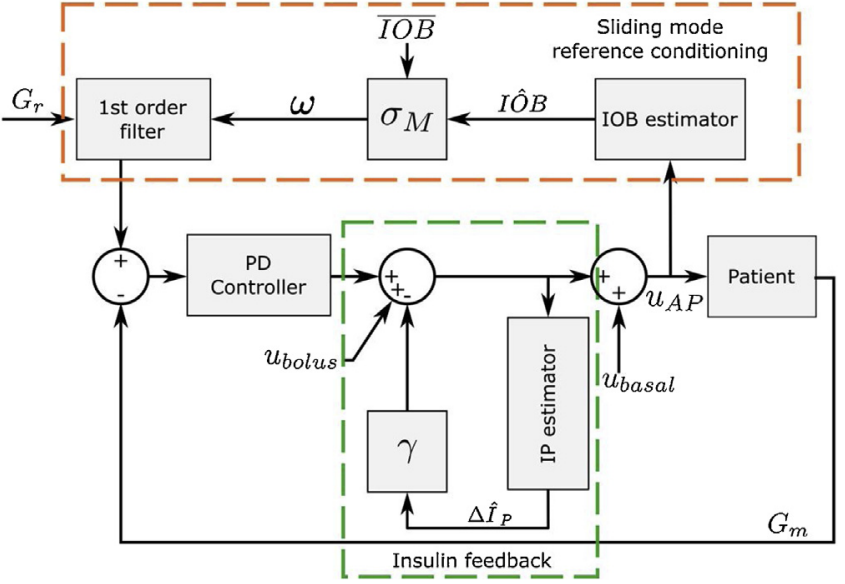

Fig. 2. Diagram of the main controller. The modules of the main controller are shown here: PD controller, Sliding mode reference conditioning and Insulin feedback. $G_{m}$, $G_{r}$ and $G_{r f}$ denote the measured glucose, the glucose set-point and the filtered setpoint respectively. $\gamma$ and $\Delta \mathrm{T}_{p}$ are the gain and the deviation of the estimated plasma insulin with respect to the basal used in the insulin feedback. $w$ is the discontinuous control action triggered by the switching function $\sigma_{S M}$ to constrain the estimated insulin-on-board $(I O B)$ to the upper bound $\overline{I O B}$.

insulin estimation $\left(I_{P}\right)$, respectively. For completeness, the basics of this controller are described below:

\subsubsection{Proportional derivative controller}

The PD controller reads as

$u_{P D}(t)=K_{p}\left(G_{m}(t)-G_{r f}(t)\right)+K_{p} T_{d} \dot{G}_{m}(t)$

where $G_{m}(t)$ is the measured glucose, $K_{p}$ is the proportional gain tuned with the 1500-rule [22] and $T_{d}$ is the derivative time set to $60 \mathrm{~min}$.

\subsubsection{Sliding mode reference conditioning}

The SMRC [23] modulates the PD glucose set-point such that $T O B(t)$ remains bounded by the upper IOB limit, $\overline{I O B}(t)$, which could be time-variant, although in this work it will be considered constant. The SMRC forces the sliding manifold $\Sigma:=\{x(t) \mid T O B(t)-$ $\overline{I O B}(t) \leq 0\}$ to be attractive to the system state $x(t)$, despite the presence of disturbances, by the discontinuous law

$w(t)=\left\{\begin{array}{c}W^{+}, \text {if } \sigma_{S M}(t)>0 \\ 0, \text { otherwise }\end{array}\right.$

where $W^{+}$is the upper value of $w(t)$ with a nominal value of $350 \mathrm{mg} / \mathrm{dL}$. $\sigma_{S M}$ is the sliding function given by

$\sigma_{S M}(t):=I O B(t)-\overline{I O B}(t)+\sum_{i=1}^{l-1} \Gamma_{i}\left(\mathcal{T O B}(t)^{(i)}-\overline{I O B}(t)^{(i)}\right)$

with $l$ the relative degree between $T O B(t)$ and $w(t), \Gamma_{i}$ are the constant gains and superscripts $(i)$ denote the $i$-th derivatives.

Additionally, the estimated IOB is considered as the subcutaneous insulin in (1), i.e., $I O B(t):=I_{S C}(t)$.

Furthermore, the first order filter

$\dot{G}_{r f}(t)=-\tau_{r f} G_{r f}(t)+\tau_{r f}\left(G_{r}(t)+w(t)\right)$

ensures that all the signals are smooth in the control loop. In (5) $G_{r f}$ is the filtered glucose set-point, $G_{r}(t)$ is the original glucose target $\left(G_{r}(t)=100 \mathrm{mg} / \mathrm{dL}\right)$ and $\tau_{r f}$ is the filter rate constant which is tuned to $0.1 \mathrm{~min}^{-1}$.

Note that, from (3) and (4) it results that $l=2$, so only $\Gamma_{1}$ ( $\left.\Gamma_{1}=10 \min [16]\right)$ needs to be tuned in (4). Further, the $\overline{I O B}$ is indi- vidualized by applying a 35\% increment with respect to the basal IOB for each subject.

\subsubsection{Insulin Feedback}

The IFB in [24] mimics the auto-inhibition of endogenous insulin production by the beta cells with

$u_{I F B}(t)=u_{A P}(t)-\gamma\left(\hat{I}_{P}(t)-\hat{I}_{P}^{*}(t)\right)=u_{A P}(t)-\gamma \Delta \hat{I}_{P}(t)$

where $\gamma$ is the controller gain $(\gamma=0.42 \mathrm{~L} / \mathrm{min})$ and $\Upsilon_{P}^{*}$ is the estimated plasma insulin in basal conditions. Unlike in [25], here, the deviation regarding the plasma insulin is employed, to avoid retuning the PD for keeping the steady state conditions of the PD without IFB.

Finally, $I_{P}(t)$ and $T^{*}{ }_{P}(t)$ are calculated with the first two equations in (1), although only the basal insulin rate is considered as insulin infusion to compute $\tau^{*}{ }_{P}(t)$.

\subsection{First order sliding mode-based rate of glucose appearance estimation}

\subsubsection{First order sliding mode observer}

The FOSMO is used to reconstruct the disturbance $R_{A}$. In [13] a FOSMO is designed for a nonlinear perturbed system given in the following form

$$
\left\{\begin{array}{c}
\dot{x}_{1}(t) \quad=A_{11} x_{1}(t)+A_{12} x_{2}(t)+\phi_{1}(x, u) \\
\dot{x}_{2}(t)=A_{21} x_{1}(t)+A_{22} x_{2}(t)+\phi_{2}(x, u)+D_{2} f(y, u, t) \\
y(t) \quad=C_{2} x_{2}(t)
\end{array}\right.
$$

where the disturbance term $f(\cdot) \in \mathbb{R}^{q}$ only affects the measured output $y(t) \in \mathbb{R}^{p}$. In (7) $u(t) \in \mathbb{R}^{m}$ are the known inputs, whereas the system state is $x(t):=\operatorname{col}\left(x_{1}(t), x_{2}(t)\right) \in \mathbb{R}^{n}$ with $x_{2}$ the last $p$ components of $x(t) . \phi(x, u, t)=\operatorname{col}\left(\phi_{1}, \phi_{2}\right)$ is the known nonlinear term which is considered Lipschitzian with respect to $x(t)$ with $L_{\phi}$ the Lipschitz constant. Finally, $A_{11}, A_{12}, D_{2}$ and $C_{2}$ are system matrices with proper dimensions.

To design the FOSMO, the following transformation is applied,

$T=\left[\begin{array}{cc}I_{n-p} & L \\ 0_{p x(n-p)} & I_{p}\end{array}\right] \quad L=\left[\begin{array}{ll}L^{0} & 0_{(n-p) x q}\end{array}\right]$

where. $\mathrm{O}_{i x j}$. denotes a matrix of zeros with dimension $i \times j, I_{i}$ denotes the identity matrix of dimension $i$ and $L^{0} \in \mathbb{R}^{(n-p) x(p-q)}$. However, since the IVP model in (1) has the same number of measured outputs than disturbances, $L^{0}$ is undefined and therefore, $=I_{4}$. Consequently, IVP model is already expressed in the form of (7) with $x(t)=\left[I_{S C}(t), I_{P}(t), I_{E F F}(t), G(t)\right]^{T}$ and $f(t):=R_{A}(t)$ for the system matrices

$$
\begin{array}{ll}
\phi_{1}(t)=\left[\begin{array}{c}
\frac{u(t)}{\tau_{1} C_{I}} \\
0 \\
0
\end{array}\right] & \phi_{2}(t)=E G P-G(t) I_{E F F}(t) \\
A_{11}=\left[\begin{array}{ccc}
-1 / \tau_{1} & 0 & 0 \\
1 / \tau_{2} & -1 / \tau_{2} & 0 \\
0 & p_{2} S_{I} & -p_{2}
\end{array}\right] & A_{12}=\left[\begin{array}{l}
0 \\
0 \\
0
\end{array}\right] \\
A_{21}=\left[\begin{array}{lll}
0 & 0 & 0
\end{array}\right] & A_{22}=- \text { GEZI } \\
D_{2}=1 & C_{2}=1
\end{array}
$$


Table 2

Performance metrics in the rate of glucose appearance estimation.

\begin{tabular}{|c|c|c|c|}
\hline & FOSMO & GESO & P-Value \\
\hline RMSE (mg/min) & $1.060(0.448) 0.939[0.836,1.111]$ & $1.220(0.492) 1.177[0.879,1.310]$ & $1.3724 \cdot 10^{-4}$ \\
\hline AUCr breakfast & $1.081(0.625) 0.990[0.617,1.475]$ & $1.183(0.761) 1.175[0.529,1.685]$ & $1.3539 \cdot 10^{-5} 0.19373 .8250 \cdot 10^{-5}$ \\
\hline AUCr lunch & $1.168(0.570) 1.067[0.747,1.517]$ & $1.225(0.670) 1.128[0.791,1.714]$ & $3.3385 \cdot 10^{-4} 1.1305 \cdot 10^{-5} 1.1963 \cdot 10^{-8}$ \\
\hline AUCr dinner & $1.217(0.552) 1.123[0.850,1.498]$ & $1.365(0.808) 1.319[0.818,1.863]$ & $4.9558 \cdot 10^{-7} 1.6734 \cdot 10^{-10} 5.0299 \cdot 10^{-14}$ \\
\hline
\end{tabular}

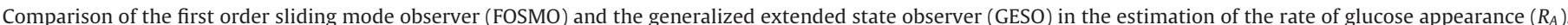

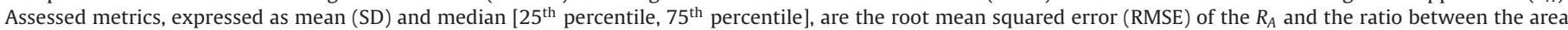

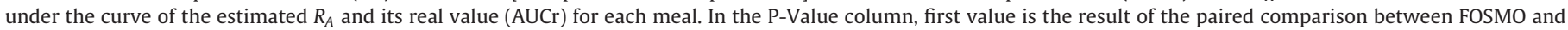
GESO. The second and third values check if mean or median of AUCr could be considered 1 for the FOSMO and GESO, respectively. by

Hence, for the system (7), the FOSMO proposed in [13] is given tor.

$\left\{\begin{array}{c}\ddot{\hat{x}}_{1}(t) \quad=A_{11} \hat{x}_{1}(t)+\phi_{1}(\hat{x}, u) \\ \dot{\hat{x}}_{2}(t)=A_{22} \hat{x}_{2}(t)+\phi_{2}(\hat{x}, u)-K\left(x_{2}-\hat{x}_{2}\right)+v(t) \\ \hat{y}(t) \quad=\hat{x}_{2}(t)\end{array}\right.$

where $\hat{x}(t):=\operatorname{col}\left(\hat{x}_{1}(t), \hat{x}_{2}(t)\right)$ and $v(t)$ is the discontinuous term which allows the state error $\left(e_{1}(t):=x_{1}(t)-\hat{x}_{1}(t) \epsilon\right.$ $\left.\mathbb{R}^{3}, e_{y}(t):=x_{2}(t)-\hat{x}_{2}(t) \in \mathbb{R}\right)$ to reach the sliding surface $S:=\left\{\left(e_{1}(t), e_{y}(t)\right) \mid e_{y}(t)=0\right\}$ and to remain there hereafter. This term is defined by,

$v(t):=\kappa(\cdot) \operatorname{sign}\left(e_{y}(t)\right)$

with $K$ and $\kappa(\cdot)$, respectively, the gain and the scalar function to be tuned such that the following conditions are satisfied [13] :

$K$ must guarantee the stability of $\left[\begin{array}{ll}A_{11} & 0 \\ 0 & C_{2} A_{22} C_{2}^{-1}+C_{2} K\end{array}\right]$.

For $e_{1}(t)$ to be asymptotically stable in $S$ the inequality $A_{11}^{T} P+$ $P A_{11}+\varepsilon P P^{T}+\frac{1}{\varepsilon_{1}} L_{\phi_{1}}^{2} I+\varepsilon_{2} P \leq 0$ must be hold with $\varepsilon_{1}$ and $\varepsilon_{2}$ positive constants, $\mathrm{P}$ the positive definite matrix used in the Lyapunov function $V:=e_{1}^{T} P e_{1}$ and $L_{\phi_{1}}$ the Lipschitz constant of $\phi_{1}$.

$e_{y}(t)$ and $e_{1}(t)$ are driven to $S$ if $\kappa(\cdot) \geq L_{\phi} \hat{w}(t)+\rho(\cdot)+\eta$ where $\eta$ is a positive constant and $\hat{w}(t)$ is the solution to $\hat{w}(t)=$ $-0.5 \varepsilon_{2} \hat{w}(t)$.

In above conditions, $\rho(\cdot)$ is the upper-bound value of the disturbance. Since this value is unavailable, an approximation is obtained by computing the maximum of the following dynamic model of the $R_{A}(t)$ in [17]

$R_{A}(t)=\frac{C_{H}}{V_{G} \tau_{m}^{2}} t \cdot \exp \left(-t / \tau_{m}\right)$

where $C_{H}$ are the ingested carbohydrates $(\mathrm{mg}), V_{G}$ is the glucose distribution volume $(\mathrm{dL})$ and $\tau_{m}$ the peak time of glucose appearance ( $\mathrm{min}$ ). To determine those parameters a realistic worst-case scenario is considered: a large meal of $C_{H}=1.2 \cdot 10^{5} \mathrm{mg}$ with a fast absorption peak ( $\tau_{m}=47 \mathrm{~min}$, chosen from Table 2 in [17]). $V_{G}$ is selected from the average adult model in the UVa-Padova simula-

\subsubsection{Rate of glucose appearance estimation}

The disturbance reconstruction is based on the concept of equivalent output error injection term $v_{e q}(t)$, i.e., the average effect of the high-frequency switching action $v(t)$ which maintains error trajectories in $S$ [13].

Remind that, once the sliding surface is reached, $e_{y}(t)=\dot{e}_{y}(t)=0$ and $e_{1}(t) \rightarrow 0$ (see Proposition 3.2 and 3.3 in [13]). As a result, the disturbance $f(\cdot):=R_{A}$ can be reconstructed form the output error dynamic as

$v_{e q}(t) \rightarrow f(y, u, t)$ where an estimation of $v_{e q}, \hat{v}_{e q}$, is computed by filtering the switching term with the first order filter with constant time $\tau_{f}\left(\tau_{f}=5 \mathrm{~min}\right)$,

$\tau_{f} \dot{\hat{v}}_{e q}(t)=-\hat{v}_{e q}(t)+v(t)$

Then, the estimated $R_{A}$ will be: $R_{A}(t):=f(t) \rightarrow \hat{v}_{e q}$.

\subsubsection{Implicit discretization}

Explicit discretization methods lead to numerical chattering [26], which is characterized by a zig-zag behavior of the state variables around the sliding surface. This limit cycle occurs because the single-valued sign function changes its value in every iteration. Acary et al. [27] address this problem by applying the multivalued sign function signm

$\operatorname{signm}(a)= \begin{cases}1 & \text { if } a>0 \\ -1 & \text { if } a<0 \\ {[-1,1]} & \text { if } a=0\end{cases}$

The implicit discretization of (10) applied to the IVP model reads as

$\left\{\begin{aligned} \hat{x}_{1}(k+1) & =\left(I_{3}+d t A_{11}\right) \hat{x}_{1}(k)+d t \phi_{1}(\hat{x}, u) \\ \hat{x}_{2}(k+1) & =\left(1+d t A_{22}\right) \hat{x}_{2}(k)+d t \phi_{2}(\hat{x}, u) \\ & -d t K\left(y(k)-\hat{x}_{2}(k)\right)+d t v(k+1)\end{aligned}\right.$

where $d t$ is the sample time, $k$ denotes the iteration and $v(k+1)$ is defined by the ensuing set-valued relation

$v(k+1) \in \kappa(\cdot) \operatorname{sgnm}\left(e_{y}(k+1)\right)$

To calculate a causal expression for $v(k+1)$, two properties of convex sets are considered [28]:

- The inverse function of the multivalued sign function $b \in$ $\operatorname{signm}(a)$ is defined as

$b \in \operatorname{sgnm}(a) \leftrightarrow a \in N_{[-1,1]}$

with $N_{[-1,1]}(b)$ the normal cone onto the convex set $[-1,1]$ at point $b$.

For a symmetric positive definite matrix $M \in \mathbb{R}^{r \times r}$ and a closed, convex and non-empty set $C \subseteq \mathbb{R}^{r}$ then

$M(b-a) \in-N_{C}(b) \leftrightarrow b=\operatorname{proj}(C ; a)$

where $\operatorname{proj}(C ; a)$ is the Euclidean projection of the point $a$ into $C$.

After applying the above properties, $v(k+1)$ is determined by

$v(k+1)=\operatorname{proj}\left(\left[-\kappa(\cdot) C_{2}^{-1}, \kappa(\cdot) C_{2}^{-1}\right] ; \frac{(1-d t G E Z I+d t K)}{d t} e_{y}(k)+f(k)\right)$

\subsection{Super-twisting-based meal detector}

Here, the identification of the meal onset is addressed as a fault detection problem. Firstly, the residuals, i.e., the inconsistencies between the measured glucose and the estimated glucose [29], are 
generated. Secondly, some decision rules are applied to determine the occurrence of the meal.

\subsubsection{Residuals generation}

SMO are suitable for generating residuals which are robust to uncertainties and disturbances [15]. Specifically, ST achieves the same performance as first order sliding mode observer in terms of robustness against matched disturbances but alleviating the problem of chattering since the discontinuity is hidden in the derivative. The ST algorithm reads as [30]

$$
\left\{\begin{array}{c}
\dot{\tilde{z}}_{1}(t)=\tilde{z}_{2}(t)-k_{1}\left|\tilde{z}_{1}(t)\right|^{\frac{1}{2}} \operatorname{sign}\left(\tilde{z}_{1}(t)\right) \\
\dot{\tilde{z}}_{2}(t) \quad=F(t)-k_{2} \operatorname{sign}\left(\tilde{z}_{1}(t)\right)
\end{array},\right.
$$

where $z_{1}(t) \in \mathbb{R}$ and $z_{2}(t) \in \mathbb{R}$ are the states of ST, $F(t)$ is the lumped disturbance which is upper-bounded by $f^{+}$; and $k_{1}$ and $k_{2}$ are gains to be designed. If $k_{1}$ and $k_{2}$ satisfy certain conditions, then $z_{1}(t)$ and $\dot{z}_{1}(t)$ will converge to 0 (see [30], [31] or [32] for different approaches) after a finite time despite the disturbance $F(t)$. The tuning in [31]

$k_{1}=1.1 f^{+} \quad k_{2}=1.5\left(f^{+}\right)^{\frac{1}{2}}$

is employed since it is a compromise option between accuracy and fast convergence.

In the context of fault detection, $z_{1}(t):=z_{1}(t)-\hat{z}_{1}(t)$ is the residual between the measured signal $z_{1}(t)$ and its estimation $\hat{z}_{1}(t)$, and $F(t)$ is the fault to be detected. To detect the fault, residual must be sensitive to $(t)$, therefore the term $f^{+}$must be fixed such that $z_{1}(t)$ does not converge to 0 at certain level of $F(t)$.

To design a residual generator for meal detection, consider the two last equations in (1) and apply the transformation

$z_{1}(t):=G(t)$

$z_{2}(t):=-\left(G E Z I+I_{E F F}(t)\right) G(t)+E G P$

which leads to the dynamic system given by

$\left\{\begin{array}{l}\dot{z}_{1}(t)=z_{2}(t)+R_{A}(t) \\ \dot{z}_{2}(t)=f_{z}\left(z_{1}, z_{2}, u_{A P}(t)\right)+p_{z}\left(z_{1}, z_{2}\right) R_{A}(t)\end{array}\right.$

where $f_{z}\left(z_{1}, z_{2}, I_{D}\right)$ and $p_{z}\left(z_{1}, z_{2}\right)$ are defined as

$f_{z}\left(z_{1}, z_{2}, I_{D}\right)=p_{2}\left(E G P-z_{2}-G E Z I z_{1}-S_{I} I_{D} z_{1}\right)+z_{2}^{2} / z_{1}-E G P z_{2} / z_{1}$

$p_{z}\left(z_{1}, z_{2}\right) \quad=\left(z_{2}-E G P\right) / z_{1}$

Now, let design a ST differentiator [31] for $z_{1}(t)$ written by,

$\left\{\begin{array}{l}\dot{\hat{z}}_{1}(t)=u_{1}(t)+k_{1}\left|\tilde{z}_{1}(t)\right|^{1 / 2} \operatorname{sign}\left(\tilde{z}_{1}(t)\right) \\ \dot{u}_{1}(t)=k_{2} \operatorname{sign}\left(\tilde{z}_{1}(t)\right)\end{array}\right.$

where $u_{1}(t)$ is an auxiliary input. Observe that the residual dynamics,

$\left\{\begin{array}{l}\dot{\tilde{z}}_{1}(t)=z_{2}(t)-u_{1}(t)-k_{1}\left|\tilde{z}_{1}(t)\right|^{1 / 2} \operatorname{sign}\left(\tilde{z}_{1}(t)\right)+R_{A}(t) \\ \dot{u}_{1}(t)=k_{2} \operatorname{sign}\left(\tilde{z}_{1}(t)\right)\end{array}\right.$

do not resemble the ST algorithm given in (20). By defining $\xi(t):=z_{2}(t)-u_{1}(t)+R_{A}(t)$ the residual dynamics are transformed into

$$
\left\{\begin{array}{l}
\dot{\tilde{z}}_{1}(t)=\tilde{\xi}(t)-k_{1}\left|\tilde{z}_{1}(t)\right|^{1 / 2} \operatorname{sign}\left(\tilde{z}_{1}(t)\right) \\
\dot{\tilde{\xi}}(t)=-k_{2} \operatorname{sign}\left(\tilde{z}_{1}(t)\right)+f_{z}\left(z_{1}, z_{2}, I_{D}\right)+p_{z}\left(z_{1}, z_{2}\right) R_{A}(t)+\dot{R}_{A}(t)
\end{array}\right.
$$

which has the form of (20) with $F(t):=f_{z}\left(z_{1}, z_{2}, I_{D}\right)+$ $p_{z}\left(z_{1}, z_{2}\right) R_{A}(t)+\dot{R}_{A}(t)$. Note that $F(t)$ depends on the disturbance and its derivative so $F(t)$ will have peaks at meal onset which would exceed the term $f^{+}$and consequently the residual would not be 0 anymore. However, $F(t)$ also depends on the unmodeled dynamics so $f^{+}$must be set higher enough for unmodeled dynamics to avoid breaking the convergence of the residuals.

\subsubsection{Decision rule for diagnosis}

After residual generation, some rules are applied to determine if a new meal is detected. Specifically, a new detection is considered if the residuals exceed a certain threshold and $G_{m}(t)$ increases at certain rate. Additionally, to avoid multiple detections triggered by a single meal, two detections will be separated at least by a selected time window.

\subsection{Feedforward actions}

\subsubsection{Bolusing algorithm}

The bolusing algorithm delivers a series of boluses, $B(k)$, targeting postprandial control of unannounced meal. The algorithm is described below:

First, at a positive detection, a conservative bolus is computed as follows

$B(k=0)=\frac{\alpha}{I C R}+\min \left(0, \frac{G_{m}-G_{r}}{C F}\right)$,

where ICR is the insulin-to-carbohydrate ratio $(\mathrm{g} / \mathrm{U})$ and $C F$ is the correction factor $(\mathrm{mg} / \mathrm{dL} / \mathrm{U})$ of the standard open-loop therapy [33]. $\alpha$ is the equivalent meal bolus and it is set to $8 \mathrm{~g}$, after exhaustive simulation, because this tuning would unlikely cause a hypoglycemia within a false positive (FP) while it would serve as a corrective bolus if this FP is due to the intrapatient variability.

Afterwards, a series of boluses is delivered. The size of these boluses responds to the following PD-like algorithm added to a constant $\alpha$-g equivalent meal bolus:

$B(k>0)=\frac{\alpha}{I C R}+k_{p}\left(G_{m}-G_{r}\right)+k_{d} \dot{G}_{m}$

where $k_{p}$ and $k_{d}$ are tuned as,

$k_{p}=\frac{\exp \left(\frac{t-t_{2 \text { ndbolus }}}{\beta}\right)}{C F} k_{d}=\left\{\begin{array}{ll}\frac{T D I}{100} & \text { if } \dot{G}_{m} \geq 0 \\ \frac{T D I}{85} & \text { if } \dot{G}_{m}<0\end{array}\right.$,

with $t$ the current time ( $\mathrm{min}), t_{2 n d b o l u s}$ the time corresponding to the second bolus, $\beta$ the exponential decay time constant $\left(\mathrm{min}^{-1}\right)$ and TDI the subject-individualized total daily insulin (U/day). The exponential decay ratio is imposed to the $k_{p}$ to reduce hypoglycemia events caused by large delayed boluses. In this regard, the asymmetric tuning of the $k_{d}$ allows more aggressiveness when hypoglycemia events are more likely to happen (negative derivatives). The coefficients of $k_{d}$ and $\beta$ (set to $50 \mathrm{~min}^{-1}$ ) are selected heuristically through extensive simulations.

A new bolus is delivered if the meal size corresponding to the previous bolus has been absorbed. An approximation of the absorbed carbohydrates is computed with the area under the curve (AUC) of the estimated mass $R_{A}$ (i.e., $R_{A} \cdot V_{G}, \mathrm{mg} / \mathrm{min}$ ) according to

\section{2}


the trapezoidal rule. The meal size related to the previous bolus is obtained by,

$C H(k-1)=B(k-1) \cdot I C R$

where $B(k-1)$ is the preceding bolus.

Remark that, because of the imposed exponential decay, the temporal separation between boluses will decrease as time goes on, since the AUC condition will be satisfied more often. This behavior at the end of the postprandial period could lead to a late insulin over delivery. Additionally, due to uncertainties coupled to the estimated $R_{A}$, the condition $A U C>\alpha$ could be satisfied for FP cases which would trigger a deleterious bolus leading to hypoglycemia. For these reasons, the following conditions have been set to stop bolusing:

\section{- Transition from hyperglycemia to normoglycemia: Since the} bolusing algorithm targets reducing postprandial glucose excursions, if once the glucose has been above $180 \mathrm{mg} / \mathrm{dL}$, it recovers the normoglycemia condition, then no additional bolus will be delivered.

- Threshold on the estimated $R_{A}$ : When $R_{A}$ becomes 0 after a detection means that meal has been absorbed, hence no additional bolus is needed. Because of uncertainties coupled to $R_{A}$, a threshold of $0.6 \mathrm{mg} / \mathrm{dL} / \mathrm{min}$ was fixed instead of 0 .

- Time window: Additional boluses are avoided if more than 150 min have elapsed since detection time.

- Condition on glucose slope from detection point to current time: Above conditions avoid retarded boluses in TP events but, they might fail in FP. To be more restrictive with FPs the instant when the slope of the line joining the glucose at detection time and the current time goes below a threshold near 0 is considered to stop delivering the bolus. The main assumption is that the first bolus has a larger impact on lowering glucose in a FP than in a TP, so the time it takes the slope to go below that threshold is less than in a TP. As a result, the bolusing algorithm deactivates before the AUC of the $R_{A}$ is large enough to deliver a second bolus.

\subsubsection{Complementary feedforward action}

One of the strengths of the SMRC in a hybrid closed-loop system is that the continuous control infusion $u_{P D}(t)$ (see Fig. 3 in red) becomes 0 right after a pre-meal bolus violates $\overline{I O B}$. Nonetheless, if boluses are delivered later than meal consumption, as it is the case for the proposed system, then the SMRC takes longer to make $u_{P D}(t)=0$ (see Fig.3 in blue). That happens because, before detecting the meal, there is no feedforward action that helps SMRC-IFB to compensate the meal. Consequently, the $u_{P D}(t)$ magnitude in the meal-announcement-free case is larger than the meal-announcement case, so $w(t)$ must be larger to shut off the pump earlier. Therefore, the feedforward action consists in increasing $W^{+}$(particularly, a 65\% with respect to its nominal value) when the conditions for delivering a second bolus are satisfied. $W^{+}$will return to its nominal value, i.e., $W^{+}=350 \mathrm{mg} / \mathrm{dL}$, when the stop conditions of the bolusing algorithm are held.

\subsection{Tuning guidelines}

Here, a brief guideline is provided to tune the main parameters in a real implementation.

Regarding the meal detector algorithm, the larger $f^{+}$is, the lower the residuals are, so, $f^{+}$should be set to the minimum value needed for the residual to be near 0 in basal conditions In addition, when increasing time window size, FPs will reduce in detriment of increasing the time detection or even, decreasing sensitivity. Moreover, the larger the residual threshold the less likely the FP events are, but sensitivity is reduced. Finally, when increasing glucose derivative threshold, the FPs will decrease at the price of a longer delay in detection and a larger number of false negatives (FN). Finally, concerning the bolus algorithm, a large value of $\beta$ leads to an aggressive control.

\subsection{In silico validations}

\subsubsection{Scenarios}

UVa-Padova simulator, extended with different sources of variability, was used to configure two scenarios for the assessment. Scenario 1 involved the 10 adults included in the academic version of the simulator by repeating three times every patient. i.e., with different instances of random variability. It was a 14-day scenario with 3 daily random meals of 45,80 and $60 \mathrm{~g}$ at 7,14 and $21 \mathrm{~h}$, respectively. Standard deviation for the meal time was $\pm 10 \mathrm{~min}$ and the coefficient of variance for the meal size was $\pm 20 \%$. Each meal had an absorption profile randomly chosen from available meal profiles in the simulator. Meal absorption rate, carbohydrate bioavailability and the subcutaneous insulin absorption rate varied at each meal following a uniform distribution of $\pm 30 \%, \pm 10 \%$ and \pm $30 \%$, respectively. Additionally, the insulin sensitivity was affected by sinusoidal circadian variations with 24 -h period, random amplitude according to a uniform distribution of $\pm 30 \%$ and random phase [34]. Moreover, sensor errors were considered according to the default model of the simulator.

Scenario 2 was a 30-day scenario of 3 daily meals. The other characteristics (meal dose, variability and noise) were configured as in Scenario 1.

\subsubsection{Performance tests}

Three validations were performed in this work. Validation 1 targeted FOSMO and GESO comparison in estimating $R_{A}$. It was performed under the Scenario 1 and it measured the quality of the estimation through the RMSE between the $R_{A}$ and $R_{A}$; and the AUC ratio for every type of meal (AUCr breakfast, AUCr lunch and $\mathrm{AUCr}$ dinner). The AUC ratio denotes the quotient between the AUC of mass $R_{A}$ and the AUC of mass $R_{A}$.

Validation 2 assessed the meal detector algorithm under the Scenario 1 . The metrics used in [10] were considered:

- The number of true positives (TP) defining the number of correct detections that the algorithm has detected in less than $120 \mathrm{~min}$ from the onset of the meal.

- The number of false positives (FP) indicating a detection without a meal. To compare the FP among dissimilar scenarios the false positive per day (FP/day) was also reported.

- The number of false negatives (FN) occurring when the meal was not detected in $120 \mathrm{~min}$ after its consumption.

- The sensitivity is defined as the percentage of TP regarding the total meals for each patient.

- The detection time indicating the time when a TP is detected.

Additionally, the carbohydrate content related to FN $\left(\mathrm{CHO}_{\mathrm{FN}}\right)$ was reported. Of note, in Validations 1 and 2, the controller corresponded to the SMRC-IFB without delivering boluses.

Finally, Validation 3 compared, under the Scenario 2, the proposed meal-announcement-free automatic system (FA) with: the main controller with missed bolus (NB), the main controller with ideal pre-meal bolus (IB) and the main controller with misestimated pre-meal bolus (MB). Noted that when meals were announced (IB and MB) a standard meal bolus ( $\left.B_{\text {meal }}\right)$ was delivered, that is,

$B_{\text {meal }}(t)=C H \cdot I C R \cdot \delta\left(t-t_{\text {meal }}\right)$

where $t_{\text {meal }}$ is the meal time and $\delta(\cdot)$ is the Dirac delta. Additionally, rescue carbohydrates were not provided in the comparison in any case. 


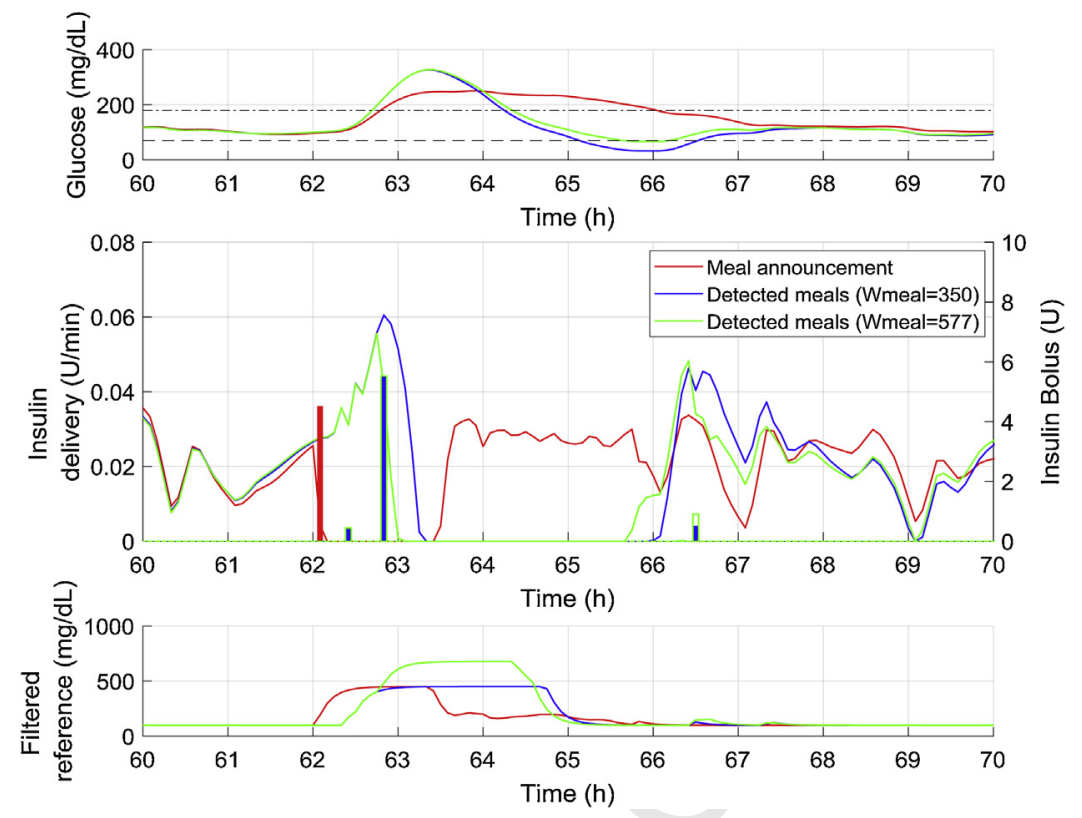

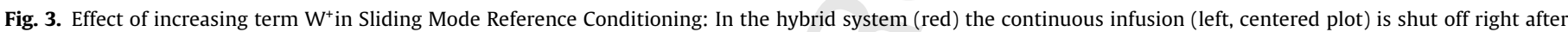

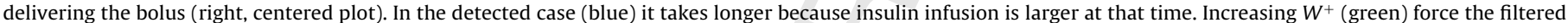
reference (bottom plot) to be higher which improves the glucose response (top plot).

The carbohydrates misestimation followed the regression curve addressed in the Fig.3 of [35], with an uniform random variability of $30 \%$ according to the maximum error observed in the referred plot. The standard metrics, i.e., \%Time in $\mathrm{G}_{\mathrm{m}}>180$, \%Time in $\mathrm{G}_{\mathrm{m}}>250$, \%Time in $\mathrm{G}_{\mathrm{m}}>300$, \%Time in $\mathrm{G}_{\mathrm{m}}<70$, \%Time in $\mathrm{G}_{\mathrm{m}}<54$, \%Time in range, mean glucose and $\mathrm{L} 1\left(\mathrm{G}_{\mathrm{m}}<70\right)$ and $\mathrm{L} 2\left(\mathrm{G}_{\mathrm{m}}<54\right)$ hypoglycemia levels, were reported. Besides, the amount of carbohydrates leading to $\mathrm{G}_{\mathrm{m}}>250$, as well as, the number of FP and FN leading to $\mathrm{G}_{\mathrm{m}}<70$ or $G_{m}>180$, respectively, also were reported. Meal detector metrics and the RMSE of the $R_{A}$ were also included to compare Scenario 1 and Scenario 2 outcomes.

\subsubsection{Statistical analysis}

All metrics referred in this paper were expressed as mean (SD) and median $\left[25^{\text {th }}\right.$ percentile, $75^{\text {th }}$ percentile].

For comparisons using the same scenario, paired t-test or Wilcoxon signed-rank test were performed, depending on their normality. When comparing metrics between Scenario 1 and Scenario 2 the non-paired t-test and the Wilcoxon rank test were used, for normal and non-normal distributions, respectively. In all cases, the significance level was 0.05 .

\section{Results and discussions}

\subsection{Validation 1: Comparison of rate of glucose appearance} observers

Fig. 4 illustrates the estimation of the observers and the real value of the $R_{A}$ computed with the UVa-Padova simulator. Either mismatch error between UVa-Padova model and IVP model or parameter uncertainties degrades estimation performance leading to an underestimation of the $R_{A}$ and, even, to some non-physiologic negative values. Despite that, both observers capture rightly the meal absorption dynamics at the meal onset, although FOSMO has lower variability. In fact, as shown in Table 2, the FOSMO significantly reduces RMSE compared to GESO (1.060 (0.448) $\mathrm{mg} / \mathrm{dL} / \mathrm{min}$ vs. $1.220(0.492) \mathrm{mg} / \mathrm{dL} / \mathrm{min}, \mathrm{p}<0.0003)$. Regarding AUC ratio, Table 2 shows values near 1 for the FOSMO than it is for the GESO in all the types of meals. Consequently, FOSMO fulfills a more accurate estimation of the ingested carbohydrate reaching plasma than GESO does. Nevertheless, although the AUC ratio can be considered 1 for the breakfast ( $p=0.104$ ) is significantly different to the simulated $R_{A}$ for lunch $\left(p=1.13 \cdot 10^{-5}\right)$ and dinner $\left(p=1.67 \cdot 10^{-10}\right)$.

To the best of the authors' knowledge, in the meal detector literature, only the work of [10] reports $\mathrm{R}_{\mathrm{A}}$-related metrics: a RMSE of $2.8 \mathrm{mg} / \mathrm{dL} / \mathrm{min}$ for a 14-day scenario with variability in meal absorption parameters. Beyond meal detector context, the off-line estimator of [12] fulfills a $0.72-\mathrm{mg} / \mathrm{dL} / \mathrm{min}$ mean RMSE for the 10 virtual patients of the UVa-Padova under a 50-g meal scenario. Although that method improves FOSMO results, it relies on plasma insulin measurement, therefore its applicability is limited to clinical environments.

\subsection{Validation 2: Meal detector algorithm assessment}

Table 3 reports a sensitivity of 90.3 (6.8)\% so the algorithm improves the $82 \%$ achieved by [6], but, other methods in the literature enhance this metric: Ramkinssoon et al.[10] report 93 (6)\% of sensitivity in their tradeoff tuning; Xie et al [8] achieves a 91\%, while Mahmoudi et al. [36] perform 99.5\%. Conversely, the proposed algorithm, with a detection time of 29.4(6.8) min, outperforms the 37 (83) $\mathrm{min}$ in [10], the 45 (14.4) $\mathrm{min}$ in [8] and the 58.4 (18.7) in [36]. Therefore, the tradeoff is between a higher sensitivity and an earlier detection of meals. Given the delay in the insulin action, in view of triggering a feedforward action after the meal detection, a short time detection will be desirable if FN-related meals do not have a too high carbohydrate content and can be dealt with the feedback controller.

Regarding FP metrics, the proposed method has an average of 1.6 (1.2) FP out of a total of 42 meal per patient and a rate of $0.1(0.1)$ FP per day. The comparison to other methods in the literature is not straightforward given the heterogeneity in the validation scenarios. Ramkinsoon et al [10] record 3 (3) FP and 0.2(0.5) FP per day in a 42 meal scenario with 47 (16) g of carbohydrate; Lee et al. [6] achieve a $6.75 \%$ of FP regarding a total of 800 meals ranged from $20 \mathrm{~g}$ to $80 \mathrm{~g}$ and Harvey et al [7] show a rate of FP per day less than 2 for a 24-h scenario with meals of 50,75 and $100 \mathrm{~g}$. 


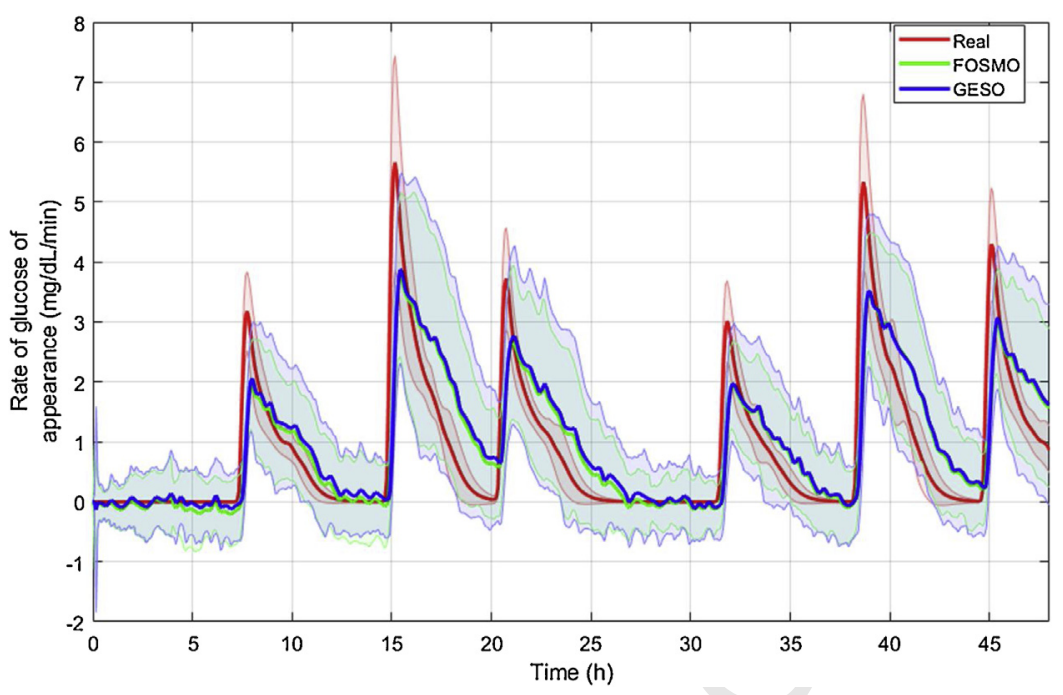

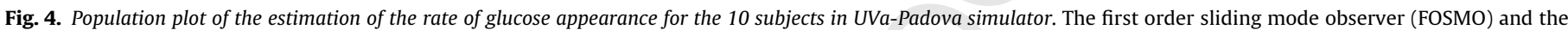

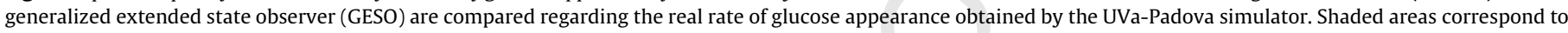
standard deviation values while solid lines are mean values. Remark, only the first $48 \mathrm{~h}$ of the simulation have been plotted for the sake of clarity.

Table 3

Meal detector performance metrics for the Validation 2.

\begin{tabular}{|c|c|c|c|c|c|c|c|}
\hline & Sensitivity (\%) & $\mathrm{TP}$ & FP & FN & $\mathrm{FP} /$ day & Detection time (min) & $\mathrm{CHO}_{\mathrm{FN}}(\mathrm{g})$ \\
\hline Mean & $90.3(6.8)$ & $37.9(2.9)$ & $1.6(1.2)$ & $4.1(2.9)$ & $0.1(0.1)$ & $29.4(6.8)$ & $49.2(4.2)$ \\
\hline Median & $90.5[85.7,97.6]$ & $38.0[36.0,41.0]$ & $1.0[1.0,2.0]$ & $4.0[1.0,6.0]$ & $0.1[0.1,0.1]$ & $30.0[25.0,30.0]$ & $48.3[46.0,52.4]$ \\
\hline
\end{tabular}

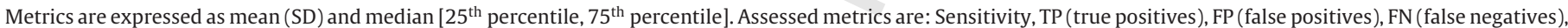
$\mathrm{FP} /$ day (false positives per day), detection time and $\mathrm{CHO}_{\mathrm{FN}}$ (carbohydrates related to false negatives). The total number of meals per patient was 42 .

Table 4

Meal detector-related metrics for Validation 3.

\begin{tabular}{|c|c|c|c|c|c|}
\hline & Sensitivity (\%) & $\mathrm{FP} /$ day & Detection time ( $\mathrm{min}$ ) & Min. glucose at FP $(\mathrm{mg} / \mathrm{dL})$ & Max. glucose at FN (mg/dL) \\
\hline Mean & $92.4(4.4)$ & $0.1(0.1)$ & $28.5(6.2)$ & $98.2(14.7)$ & $202.3(31.0)$ \\
\hline Median & $92.8[90.0,95.6]$ & $0.1[0.1,0.2]$ & $30.0[25.0,30.0]$ & $97.9[91.2,110.9]$ & $196.7[182.7,208.7]$ \\
\hline
\end{tabular}

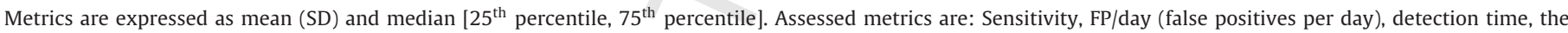
minimum glucose value $90 \mathrm{~min}$ after FP and the maximum glucose value 90 min after FN. The total number of meals per patient was 90 .

\subsection{Validation 3: Meal-announcement-free artificial pancreas} assessment

The RMSE of $R_{A}$ is slightly lower than the RMSE in Table 2, but differences are not significant (Validation 3: 1.033 (0.286) vs. Validation 1: $1.060(0.448) \mathrm{mg} / \mathrm{dL} / \mathrm{min}, p=0.6288)$. Additionally, the meal detector algorithm shows a satisfactory repeatability since either the detection time or the FP per day are close to those obtained in Section 3.2 (see Table 4). Moreover, the apparently improvement in sensitivity in Validation 3 does not have statistical significance $(p=0.325)$.

Table 5 shows that the proposed system reduces significantly all levels of hyperglycemia $\left(G_{m}>180, G_{m}>250\right.$ and $\left.G_{m}>300\right)$ regarding the missed bolus case. However, time in hyperglycemia for the proposed system is longer when comparing to either the ideal announced case or the bolus misestimation case; although, in this last case severe hyperglycemia is not statistically different (FA: $0.448(0.747) \%$ vs. MB:0.356 (1.153)\%). The longer time in hyperglycemia is due to a still long detection time and to the need for a conservative bolus at detection time in order to reduce hypoglycemia events during FP occurrences. Indeed, as observed in Fig. 5 both, the missed bolus case and the proposed case, have the same average postprandial response before the second bolus is delivered. That evidences the slow dynamics of insulin compared to meal absorption which makes challenging the meal compensation problem. In addition, the occurrence of FN events also leads to hyperglycemia. Nevertheless, out of 6.6 (3.8) of occurring FN only 1.4 (1.2) are directly related to hyperglycemia. That is because, the carbohydrate content of the meals related to FN (46.3 (4.4) g) is lower than the meal size leading to $\mathrm{G}_{\mathrm{m}}>250 \mathrm{mg} / \mathrm{dL}(83.5(7.2) \mathrm{g})$.

Although the proposed system tends to increase L1 and L2 hypoglycemia either in percent time or incidence, that rise is not significative (see Table 5). Furthermore, only $0.033(0.183)$ FP events are related to hypoglycemia Among these FP, only two events of L2 hypoglycemia are reported $(49.14 \mathrm{mg} / \mathrm{dL}$ and $45.32 \mathrm{mg} / \mathrm{dL}$ ) for the second and third instances of patient 7 , respectively. Indeed, the $25^{\text {th }}$ and $75^{\text {th }}$ percentiles of the minimum measured glucose after $90 \mathrm{~min}$ from detection are always above $70 \mathrm{mg} / \mathrm{dL}$. The fact is not only because the first bolus is conservative, but it also shows the correct choice of the stop conditions to avoid a second bolus during a FP. For example, in the $75 \%$ of all the cases the slope condition prevents for a new bolus before $35 \mathrm{~min}$ the FP occurrence.

Moreover, the proposed system significantly improves the time in range and the glucose mean compared to the missed bolus case. Although the ideal announced case fulfills better results in these metrics, the more realistic case of bolus misestimation achieves a glucose mean without significative differences regarding the proposed system (MB: 144.276(11.010) mg/dL vs. FA: 146.690(12.198) $\mathrm{mg} / \mathrm{dL}, p=0.0724)$. Thus, in both cases, the predicted glycated hemoglobin is similar with the advantage that the proposed system frees the patient from the burden of carbohydrate counting. 
Table 5

Performance metrics for the comparison between the missed bolus case, the carbohydrate misestimation case, the ideal meal announced and the detected meal case.

\begin{tabular}{|c|c|c|c|c|}
\hline & $\begin{array}{l}\text { Hybrid system with missed } \\
\text { bolus (NB) }\end{array}$ & $\begin{array}{l}\text { Hybrid system with bolus } \\
\text { misestimation }(\mathrm{MB})\end{array}$ & $\begin{array}{l}\text { Hybrid system with ideal } \\
\text { announced meals (IB) }\end{array}$ & $\begin{array}{l}\text { Meal-announcement-free } \\
\text { automatic system (FA) }\end{array}$ \\
\hline Mean $\mathrm{G}_{\mathrm{m}}(\mathrm{mg} / \mathrm{dL})$ & $\begin{array}{l}169.057(22.409) * 160.065 \\
{[157.641,193.172]}\end{array}$ & $\begin{array}{l}144.276(11.010) 141.473 \\
{[138.630,154.346]}\end{array}$ & $\begin{array}{l}138.970(9.074) * 136.954 \\
{[133.937,146.519]}\end{array}$ & $\begin{array}{l}146.690(12.198) 143.412 \\
{[139.815,148.091]}\end{array}$ \\
\hline $\mathrm{G}_{\mathrm{m}}<70$ (\%Time) & $\begin{array}{l}0.003(0.011) 0.000 \\
{[0.000,0.000]}\end{array}$ & $\begin{array}{l}0.004(0.014) 0.000 \\
{[0.000,0.000]}\end{array}$ & $\begin{array}{l}0.013(0.037) 0.000 \\
{[0.000,0.000]}\end{array}$ & $\begin{array}{l}0.029(0.077) 0.000 \\
{[0.000,0.000]}\end{array}$ \\
\hline $\mathrm{G}_{\mathrm{m}}<54$ (\%Time) & $\begin{array}{l}0.000(0.000) 0.000 \\
{[0.000,0.000]}\end{array}$ & $\begin{array}{l}0.000(0.000) 0.000 \\
{[0.000,0.000]}\end{array}$ & $\begin{array}{l}0.000(0.000) 0.000 \\
{[0.000,0.000]}\end{array}$ & $\begin{array}{l}0.005(0.018) 0.000 \\
{[0.000,0.000]}\end{array}$ \\
\hline $70 \leq \mathrm{G}_{\mathrm{m}} \leq 80$ (\%Time) & $\begin{array}{l}62.255(14.463) * 67.587 \\
{[50.289,69.063]}\end{array}$ & $\begin{array}{l}81.349(7.894) * 82.008 \\
{[78.785,86.262]}\end{array}$ & $\begin{array}{l}85.884(6.975) * 86.939 \\
{[80.949,90.938]}\end{array}$ & $\begin{array}{l}77.459(8.706) 78.958 \\
{[75.046,81.042]}\end{array}$ \\
\hline $\mathrm{G}_{\mathrm{m}}>180$ (\%Time) & $\begin{array}{l}37.743(14.463) * 32.413 \\
{[30.938,49.711]}\end{array}$ & $\begin{array}{l}18.647(7.893) * 17.992 \\
{[13.738,21.215]}\end{array}$ & $\begin{array}{l}14.103(6.971) * 13.061 \\
{[9.063,19.051]}\end{array}$ & $\begin{array}{l}22.512(8.715) 20.943 \\
{[18.958,24.954]}\end{array}$ \\
\hline $\mathrm{G}_{\mathrm{m}}>250$ (\%Time) & $\begin{array}{l}10.997(8.906) * 8.328 \\
{[4.201,18.322]}\end{array}$ & $\begin{array}{l}2.262(3.200) * 0.793 \\
{[0.208,3.056]}\end{array}$ & $\begin{array}{l}0.857(1.936) * 0.029 \\
{[0.000,0.856]}\end{array}$ & $\begin{array}{l}2.730(2.452) 2.297 \\
{[0.521,4.560]}\end{array}$ \\
\hline $\mathrm{G}_{\mathrm{m}}>300$ (\%Time) & $\begin{array}{l}3.036(4.065) * 1.383 \\
{[0.035,4.479]}\end{array}$ & $\begin{array}{l}0.450(1.297) 0.000 \\
{[0.000,0.266]}\end{array}$ & $\begin{array}{l}0.154(0.626) * 0.000 \\
{[0.000,0.000]}\end{array}$ & $\begin{array}{l}0.326(0.588) 0.029 \\
{[0.000,0.370]}\end{array}$ \\
\hline No. L1 & $\begin{array}{l}0.033(0.183) 0.000 \\
{[0.000,0.000]}\end{array}$ & $\begin{array}{l}0.067(0.254) 0.000 \\
{[0.000,0.000]}\end{array}$ & $\begin{array}{l}0.167(0.461) 0.000 \\
{[0.000,0.000]}\end{array}$ & $\begin{array}{l}0.300(0.702) 0.000 \\
{[0.000,0.000]}\end{array}$ \\
\hline No. L2 & $\begin{array}{l}0.000(0.000) 0.000 \\
{[0.000,0.000]}\end{array}$ & $\begin{array}{l}0.000(0.000) 0.000 \\
{[0.000,0.000]}\end{array}$ & $\begin{array}{l}0.000(0.000) 0.000 \\
{[0.000,0.000]}\end{array}$ & $\begin{array}{l}0.067(0.254) 0.000 \\
{[0.000,0.000]}\end{array}$ \\
\hline Mean $\mathrm{CHO}$ for $\mathrm{G}_{\mathrm{m}}>250(\mathrm{~g})$ & $\begin{array}{l}78.540(6.162) * 77.676 \\
{[72.560,82.769]}\end{array}$ & $\begin{array}{l}86.382(5.273) * 86.651 \\
{[83.976,89.917]}\end{array}$ & $\begin{array}{l}83.600(7.830) 86.250 \\
{[79.250,88.550]}\end{array}$ & $\begin{array}{l}83.674(4.862) 83.778 \\
{[80.774,86.942]}\end{array}$ \\
\hline
\end{tabular}

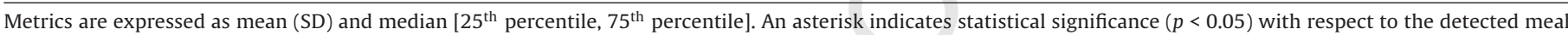

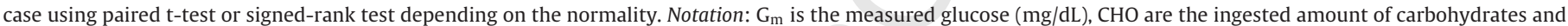
L1 and L2 denote the incidence of level 1 hypoglycemia $\left(G_{\mathrm{m}}<70 \mathrm{mg} / \mathrm{dL}\right)$ and level 2 hypoglycemia $\left(\mathrm{G}_{\mathrm{m}}<54 \mathrm{mg} / \mathrm{dL}\right)$, respectively.

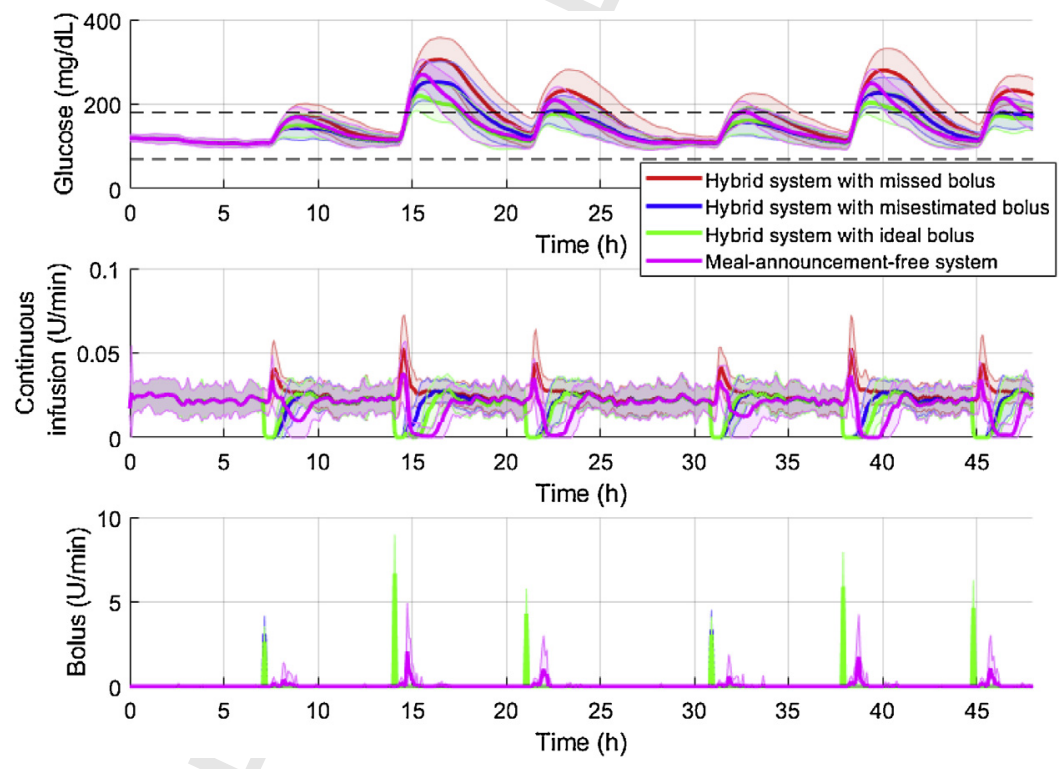

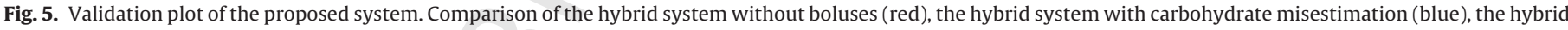

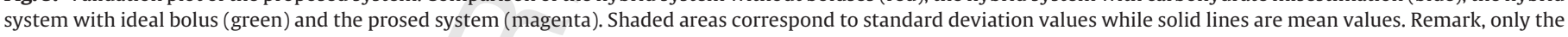
first $48 \mathrm{~h}$ of the simulation have been plotted for the sake of clarity.

Finally, several methods in literature have addressed the design of a meal-announcement-free artificial pancreas system. Lee et al [6] remove the L2 hypoglycemia, although the time in L1 hypoglycemia is higher than in the proposed algorithm. The algorithm suggested in [9] avoids hyperglycemia events and offers more than $90 \%$ in time in range. However, no source of variability seems to be added in the simulation. Finally, the results in [7] are comparable with the proposed system in terms of time in $\mathrm{G}_{\mathrm{m}}>180$ ([7]:25\% vs. FA: $22.51 \%$ ) and time in $\mathrm{G}_{\mathrm{m}}>250$ ([7]:4.7\% vs. FA:2.73\%) in a 3-meal scenario.

\section{Conclusions}

The design of a meal-announcement-free artificial pancreas has been addressed in this work by exploiting the strengths of sliding mode observers in dealing with disturbances. The proposed system includes a first order sliding mode observer to estimate the rate of glucose appearance, a super-twisting-based residual generator to detect meals and a bolusing algorithm based on a PD-like algorithm to deliver boluses according to the area under the curve of the rate of glucose appearance once meals are detected.

Three in silico validations have been performed to assess the proposed system. First validation has proved that the first order sliding mode observer outperforms our previous linear approach in the estimation of the rate of glucose appearance. In the second validation, the proposed meal detector has shown a slightly reduction in detection time with respect to other methods in the literature. The final validation has concluded that the complete system has intermediate outcomes between the hybrid system with bolus misestimation and the hybrid system with missed bolus: it manages to significantly reduce the time in hyperglycemia regarding the missed bolus case without increasing hypoglycemia, but 
this reduction is not enough to be comparable with the hybrid system with carbohydrate misestimation due to a still long detection time and the slow absorption of insulin comparing to meals.

Future work should focus on making less conservative the bolusing algorithm to reduce the postprandial glucose excursions. To reach that goal, major efforts should be done to reduce the effect of uncertainties in either the estimation of the rate of glucose appearance or the residuals to achieve a better estimation of the absorbed carbohydrates and to decrease the false positives, respectively.

\section{Funding}

This work was supported by the Spanish Ministry of Economy, Industry and Competitiveness (MINECO) [grant number DPI2016-78831-C2-1-R]; the European Union [FEDER funds]; and Generalitat Valenciana [grant number ACIF/2017/021]

\section{Declaration of interest}

None.

\section{Acknowledgments}

Authors thank anonymous reviewers for their constructive suggestions.

\section{Appendix A. Supplementary data}

Supplementary material related to this article can be found, in the online version, at doi:https://doi.org/10.1016/j.jprocont.2019. 03.008.

\section{References}

[1] R. Hovorka, Continuous glucose monitoring and closed-loop systems, Diabet. Med. 23 (2006) 1-12, http://dx.doi.org/10.1111/j.1464-5491.2005.01672.x.

[2] American Diabetes Association, Diagnosis and classification of diabetes mellitus, D. Of, D. Mellitus, Diabetes Care. 37 (2014) 81-90, http://dx.doi.org/ 10.2337/dc14-S081.

[3] A. El Fathi, V. Gingras, B. Boulet, The Artificial Pancreas and Meal Control, IEEE Control Syst. (2018).

[4] V. Gingras, N. Taleb, A. Roy-Fleming, L. Legault, R. Rabasa-Lhoret, The challenges of achieving postprandial glucose control using closed-loop systems in patients with type 1 diabetes, Diabetes, Obes. Metab. 20 (2018) 245-256, http://dx.doi.org/10.1111/dom.13052.

[5] E. Dassau, B.W. Bequette, B.A. Buckingham, F.J. Doyle III, Detection of a Meal Using Continuous Glucose Monitoring, Diabetes Care. 31 (2008) 295-300, http://dx.doi.org/10.2337/dc07-1293.B.W.B.

[6] L. Hyunjin, B.A. Buckingham, D.M. Wilson, B.W. Bequette, A closed-loop artificial pancreas using model predictive control and a sliding meal size estimator, J Diabetes Sci Technol. 3 (2009) 1082-1090 http://www.ncbi.nlm. nih.gov/pmc/articles/PMC2769914/?tool=pubmed.

[7] R.A. Harvey, E. Dassau, H. Zisser, D.E. Seborg, F.J. Doyle, Design of the Glucose Rate Increase Detector, J. Diabetes Sci. Technol. 8 (2014) 307-320, http://dx. doi.org/10.1177/1932296814523881.

[8] J. Xie, Q. Wang, A variable state dimension approach to meal detection and meal size estimation: In silico evaluation through basal-bolus insulin therapy for type 1 diabetes, IEEE Trans. Biomed. Eng. 64 (2017) 1249-1260, http://dx. doi.org/10.1109/TBME.2016.2599073.

[9] K. Turksoy, A. Cinar, Real-Time Insulin Bolusing for Unannounced Meals Using CGM Measurements, in: IFAC-PapersOnLine, Elsevier, 2015, pp. 219-224, http://dx.doi.org/10.1016/J.IFACOL.2015.10.142.

[10] C. Ramkissoon, P. Herrero, J. Bondia, J. Vehi, Unannounced Meals in the Artificial Pancreas: Detection Using Continuous Glucose Monitoring, Sensors. 18 (2018) 884, http://dx.doi.org/10.3390/s18030884.

[11] I. Sala-Mira, J.L. Díez, J. Bondia, Generalized extended state observer design for the estimation of the rate of glucose appearance in artificial pancreas, in ECC2018, Limassol (Cyprus) (2018) 2393-2398.

[12] P. Herrero, J. Bondia, C.C. Palerm, J. Vehí, P. Georgiou, N. Oliver, C. Toumazou, A simple robust method for estimating the glucose rate of appearance from mixed meals, J. Diabetes Sci. Technol. 6 (2012) 153-162, http://dx.doi.org/10 $1177 / 193229681200600119$.

[13] Y.B. Shtessel, C. Edwards, L. Fridman, A. Levant, Sliding Mode Control and Observation (2014), http://dx.doi.org/10.1007/978-0-8176-4893-0.

[14] Y. Sun, J. Yu, Z. Li, Y. Liu, Coupled disturbance reconstruction by sliding mode observer approach for nonlinear system, Int. J. Control. Autom. Syst. 15 (2017) 2292-2300, http://dx.doi.org/10.1007/s12555-016-0575-8.

[15] F.J.J. Hermans, M.B. Zarrop, Sliding Mode Observers for Robust Sensor Monitoring, IFAC Proc, Vol. 29 (1996) 6530-6535, http://dx.doi.org/10.1016/ S1474-6670(17)58730-3.

[16] I. Sala-Mira, J.L. Díez, J. Bondia, Insulin limitation in the Artificial Pancreas by Sliding Mode Reference Conditioning and Insulin Feedback: an in silico comparison, in: IFAC-PapersOnLine, 2017, pp. 7743-7748, http://dx.doi.org/ 10.1016/j.ifacol.2017.08.1153.

[17] S. Kanderian, Steil, G. Steil, Identification of Intraday Metabolic Profiles during Closed-Loop Glucose Control in Individuals with Type 1, Diabetes 3 (2009) 1047-1057, http://dx.doi.org/10.1177/193229680900300508.

[18] R.N. Bergman, L.S. Phillips, C. Cobelli, Physiologic evaluation of factors controlling glucose tolerance in man: measurement of insulin sensitivity and beta-cell glucose sensitivity from the response to intravenous glucose, J. Clin. Invest. 68 (1981) 1456-1467, http://dx.doi.org/10.1172/JCI110398.

[19] R. Hovorka, V. Canonico, L.J. Chassin, U. Haueter, M. Massi-Benedetti, M.O. Federici, T.R. Pieber, H.C. Schaller, L. Schaupp, T. Vering, M.E. Wilinska, Nonlinear model predictive control of glucose concentration in subjects with type 1 diabetes, Physiol. Meas. 25 (2004) 905-920, http://dx.doi.org/10.1088/ 0967-3334/25/4/010.

[20] C. Dalla Man, F. Micheletto, D. Lv, M. Breton, B. Kovatchev, C. Cobelli, The UVA/PADOVA type 1 diabetes simulator: New features, J. Diabetes Sci. Technol. 8 (2014) 26-34, http://dx.doi.org/10.1177/1932296813514502.

[21] K. van Heusden, E. Dassau, H.C. Zisser, D.E. Seborg, F.J. Doyle, Control-Relevant Models for Glucose Control Using A Priori Patient Characteristics, IEEE Trans. Biomed. Eng. 59 (2012) 1839-1849, http://dx.doi.org/10.1109/TBME.2011. 2176939.

[22] C.C. Palerm, Physiologic insulin delivery with insulin feedback: A control systems perspective, Comput. Methods Programs Biomed. 102 (2011) 130-137, http://dx.doi.org/10.1016/j.cmpb.2010.06.007.

[23] A. Revert, F. Garelli, J. Pico, H. De Battista, P. Rossetti, J. Vehi, J. Bondia, Safety Auxiliar Feedback Element for the Artificial Pancreas in Type 1 Diabetes, Biomed. Eng. IEEE Trans. 60 (2013) 2113-2122.

[24] J. Bondia, S. Romero-Vivo, B. Ricarte, J.L. Diez, Insulin Estimation and Prediction: A Review of the Estimation and Prediction of Subcutaneous Insulin Pharmacokinetics in Closed-Loop Glucose Control, IEEE Control Syst. 38 (2018) 47-66, http://dx.doi.org/10.1109/MCS.2017.2766312.

[25] G.M. Steil, C.C. Palerm, N. Kurtz, G. Voskanyan, A. Roy, S. Paz, F.R. Kandeel, The effect of insulin feedback on closed loop glucose control, J. Clin. Endocrinol. Metab. 96 (2011) 1402-1408, http://dx.doi.org/10.1210/jc.2010-2578.

[26] Z. Galias, X. Yu, Euler's discretization of single input sliding-mode control systems, IEEE Trans. Automat. Contr. 52 (2007) 1726-1730, http://dx.doi.org/ 10.1109/TAC.2007.904289.

[27] V. Acary, B. Brogliato, Implicit Euler numerical simulations of sliding mode systems, Res. Rep. RR-6886. (2009) 17-20.

[28] V. Acary, O. Bonnefon, B. Brogliato, Nonsmooth Modeling and Simulation for Switched Circuits, Springer Netherlands, Dordrecht, 2011, http://dx.doi.org/ 10.1007/978-90-481-9681-4.

[29] V. Venkatasubramanian, R. Rengaswamy, S.N. Ka, A review of process fault detection and diagnosis, Part I: Quantitative model-based methods Venkat 27 (2003) 313-326

[30] J. Davila, L. Fridman, A. Levant, Second-order sliding-mode observer for mechanical systems, IEEE Trans. Automat. Contr. 50 (2005) 1785-1789, http://dx.doi.org/10.1109/TAC.2005.858636.

[31] A. Levant, Robust Extract Differentiation via Sliding mode Technique, Automatica. 34 (1998) 379-384.

[32] J.A. Moreno, M. Osorio, A Lyapunov approach to second order sliding mode controller and observers, 47th Conf. Decis. Control. (2008) 2856-2861, http:/ dx.doi.org/10.1109/CDC.2008.4739356.

[33] S. Schmidt, K. Norgaard, Bolus calculators, J. Diabetes Sci. Technol. 8 (2014) 1035-1041, http://dx.doi.org/10.1177/1932296814532906.

[34] M.E. Wilinska, L.J. Chassin, C.L. Acerini, J.M. Allen, D.B. Dunger, R. Hovorka, Simulation environment to evaluate closed-loop insulin delivery systems in type 1 diabetes, J. Diabetes Sci. Technol. 4 (2010) 132-144, http://dx.doi.org/ $10.1177 / 193229681000400117$.

[35] T. Kawamura, C. Takamura, M. Hirose, T. Hashimoto, T. Higashide, Y. Kashihara, K. Hashimura, H. Shintaku, The factors affecting on estimation of carbohydrate content of meals in carbohydrate counting, Clin. Pediatr. Endocrinol. 24 (2015) 153-165, http://dx.doi.org/10.1297/cpe.24.153.

[36] Z. Mahmoudi, K. Nørgaard, N.K. Poulsen, H. Madsen, J.B. Jørgensen, Fault and meal detection by redundant continuous glucose monitors and the unscented Kalman filter, Biomed. Signal Process. Control. 38 (2017) 86-99, http://dx.doi. org/10.1016/j.bspc.2017.05.004.

704

705

706 